\title{
Clostridium difficile has a single sortase, SrtB, that can be inhibited by small-molecule inhibitors
}

\author{
Elizabeth H Donahue', Lisa F Dawson'1, Esmeralda Valiente', Stuart Firth-Clark², Meriel R Major², Eddy Littler², \\ Trevor R Perrior ${ }^{2}$ and Brendan W Wren ${ }^{1 *}$
}

\begin{abstract}
Background: Bacterial sortases are transpeptidases that covalently anchor surface proteins to the peptidoglycan of the Gram-positive cell wall. Sortase protein anchoring is mediated by a conserved cell wall sorting signal on the anchored protein, comprising of a C-terminal recognition sequence containing an "LPXTG-like" motif, followed by a hydrophobic domain and a positively charged tail.

Results: We report that Clostridium difficile strain 630 encodes a single sortase (SrtB). A FRET-based assay was used to confirm that recombinant SrtB catalyzes the cleavage of fluorescently labelled peptides containing (S/P)PXTG motifs. Strain 630 encodes seven predicted cell wall proteins with the (S/P)PXTG sorting motif, four of which are conserved across all five C. difficile lineages and include potential adhesins and cell wall hydrolases. Replacement of the predicted catalytic cysteine residue at position 209 with alanine abolishes SrtB activity, as does addition of the cysteine protease inhibitor MTSET to the reaction. Mass spectrometry reveals the cleavage site to be between the threonine and glycine residues of the (S/P)PXTG peptide. Small-molecule inhibitors identified through an in silico screen inhibit SrtB enzymatic activity to a greater degree than MTSET.
\end{abstract}

Conclusions: These results demonstrate for the first time that $C$. difficile encodes a single sortase enzyme, which cleaves motifs containing (S/P)PXTG in-vitro. The activity of the sortase can be inhibited by mutation of a cysteine residue in the predicted active site and by small-molecule inhibitors.

Keywords: Clostridium difficile, Sortase, Cysteine protease, Fluorescence resonance energy transfer (FRET), Enzyme kinetics, Enzyme inhibitors

\section{Background}

Sortases are membrane-bound cysteine transpeptidases that anchor surface proteins to the peptidoglycan cell wall in Gram-positive bacteria. Surface proteins anchored via sortases are often essential virulence factors important in colonization and invasion, evasion of the host immune system, and nutrient acquisition. The sorting process is mediated by a conserved C-terminal cell wall sorting signal on the anchored protein, comprised of a C-terminal recognition sequence (often LPXTG, where $\mathrm{X}$ is any amino acid), followed closely by a hydrophobic transmembrane domain and a positively charged tail [1]. A conserved catalytic cysteine residue of the sortase cleaves the LPXTG motif of the polypeptide between the threonine

\footnotetext{
* Correspondence: brendan.wren@lshtm.ac.uk

${ }^{1}$ Pathogen Molecular Biology Department, London School of Hygiene and

Tropical Medicine, Keppel Street, London WC1E 7HT, UK

Full list of author information is available at the end of the article
}

and glycine residues and covalently attaches the protein to the peptidoglycan [2-6].

There are six described sortase families, A-F, that share amino acid similarity [7]. All catalyze similar transpeptidation reactions, but recognize different substrate motifs and serve different functions within the cell. Class A sortases (SrtA), such as the prototypical Staphylococcus aureus Sortase A (SaSrtA), are considered housekeeping sortases as they are capable of anchoring many functionally distinct proteins to the cell wall. SaSrtA, which recognizes an LPXTG motif, is responsible for anchoring a variety of surface proteins involved in adherence and immune response evasion, and is essential for virulence in animal models $[8,9]$. SrtA orthologues have been found in the genomes of almost all Gram-positive bacteria [8,10-16]. Class B sortases are functionally different from class A in their substrate specificity. In $S$. aureus and $B$. anthracis, the sortase B gene (srtB) is part of an iron- 
regulated locus isd (iron-responsive surface determinant) responsible for heme-iron transport, and anchors the iron transporter protein, IsdC, by recognizing an NPQTN motif $[17,18]$. Though mutating $\operatorname{srtB}$ has no effect on establishing infection, SaSrtB is required for persistence of the bacterium in mice [17].

Clostridium difficile, an anaerobic Gram-positive, sporeforming bacillus, is the leading cause of hospital-acquired infectious diarrhea in North America and Europe. Infection with $C$. difficile can result in a range of clinical presentations, from mild self-limiting diarrhea to the life-threatening pseudomembranous colitis (PMC), known collectively as $C$. difficile infection (CDI) [19]. MLST studies have identified that the $C$. difficile population structure forms at least five distinct lineages that are all associated with CDI [20-22]. Complications of severe CDI can lead to toxic megacolon, bowel perforation, sepsis and death in up to $25 \%$ of cases [23]. Broad-spectrum antibiotic usage is the greatest risk factor for development of CDI due to the consequent disruption of the intestinal microflora. Treatment of CDI with metronidazole and vancomycin can exacerbate the problem by continuing to disrupt the intestinal microflora. This leaves the patient susceptible to relapse or re-infection. Approximately one third of patients experience CDI relapse following treatment, and those who relapse have a greater risk of succumbing to the infection [23]. A current imperative is the development of therapies that selectively target $C$. difficile, whilst leaving the intestinal microflora intact.

The $C$. difficile reference strain 630 encodes a single predicted sortase, CD630_27180, which has high aminoacid similarity with SrtB of $S$. aureus and B. anthracis [24]. A second sortase encoded within the genome is interrupted by a stop codon prior to the catalytic cysteine and is considered a pseudogene. Thus, in contrast to other Gram-positive bacteria, $C$. difficile appears to have only a single functional sortase. As such, a compound that inhibits the activity of $C$. difficile sortase could target the pathogen without disrupting the numerous Gram-negative bacteria that make up the intestinal flora.

In this study, we demonstrate that the predicted sortase encoded by CD630_27180 recognizes and cleaves an (S/P)PXTG motif between the threonine and glycine residues. The cleavage of this motif is dependent on the conserved cysteine residue at position 209 in the predicted active site of the sortase. We have also identified seven putative sortase substrates, all of which contain the (S/P)PXTG motif. These substrates are conserved among the five $C$. difficile lineages and include potential adhesins, a 5' nucleotidase, and cell wall hydrolases. Furthermore, we identified a number of small-molecule inhibitors by means of an in silico screen that inhibit the activity of the C. difficile SrtB.

\section{Results}

Conservation of the catalytically active residues of sortase The genome sequence of $C$. difficile strain 630 previously indicated the presence of a single copy of a sortase-like protein, encoded by CD630_27180, based on the presence of the sortase catalytic motif TLXTC [24]. We performed BLAST searches (BlastP) to reveal the protein encoded by CD630_27180 shares 32\% and 34\% amino acid identity with SrtB from $S$. aureus (SaSrtB) and B. anthracis (BaSrtB), respectively. In addition to the TLXTC active site, the catalytically essential histidine (His120 in SaSrtA) and arginine (R197 in SaSrtA) residues $[3,25,26]$ are conserved in the $C$. difficile SrtB. A structural prediction analysis of SrtB was performed using Phyre2 Protein Fold Recognition Server (http://www.sbg.bio.ic.ac.uk/phyre2/ $\mathrm{html} /$ page.cgi?id=index) [27], and the resulting alignment suggests a high level of conservation between the predicted secondary structure of SrtB and the known crystal structure of the BaSrtB [28] (Figure 1). Expression of $C$. difficile SrtB was analysed in vitro using RT-PCR analysis on strain 630, which confirmed that CD2718 is actively transcribed during early exponential, late exponential and stationary phases (Additional file 1: Figure S1).

The $C$. difficile population structure forms at least five distinct clonal lineages that are all associated with human infection [20-22]. To determine whether SrtB is conserved between $C$. difficile strains, representatives for each of the five distinct clades were chosen for analysis based on the availability of a fully annotated sequence: C. difficile strains 630 for Clade 1, R20291 and CD196 (RT027) for Clade 2 [29], M68 and CF5 (RT017) for Clade 3 [20], CD305 (RT023) for Clade 4 (unpublished, WTSI), and M120 (RT078) for Clade 5 [20]. BLAST searches of these representative strains show that $\operatorname{srt} B$ is conserved across all five $C$. difficile lineages. A second sortase-like gene in the 630 genome, classified as a pseudogene because of an in frame stop codon prior to the catalytic cysteine, is absent from the other four $C$. difficile lineages.

\section{Bioinformatic prediction of sortase substrates}

A bioinformatics approach was used for the preliminary identification of sortase substrate proteins in $C$. difficile strain 630 . The predicted recognition sequence for CD630_27180 has been proposed to be (S/P)PXTG by Pallen et al. [11], and recently to also include the sequence NVQTG, found in the surface- associated collagen binding protein CbpA, by Tulli et al. [30]. Putative proteins were screened for the patterns (S/P)PXTG and NVQTG at the $\mathrm{C}$-terminus $[11,30]$. Putative candidates were then assessed for the known features of a sortase substrate: a predicted N-terminal signal peptide sequence, and a cell wall sorting signal comprising of a potential transmembrane domain following the sortase recognition sequence, 


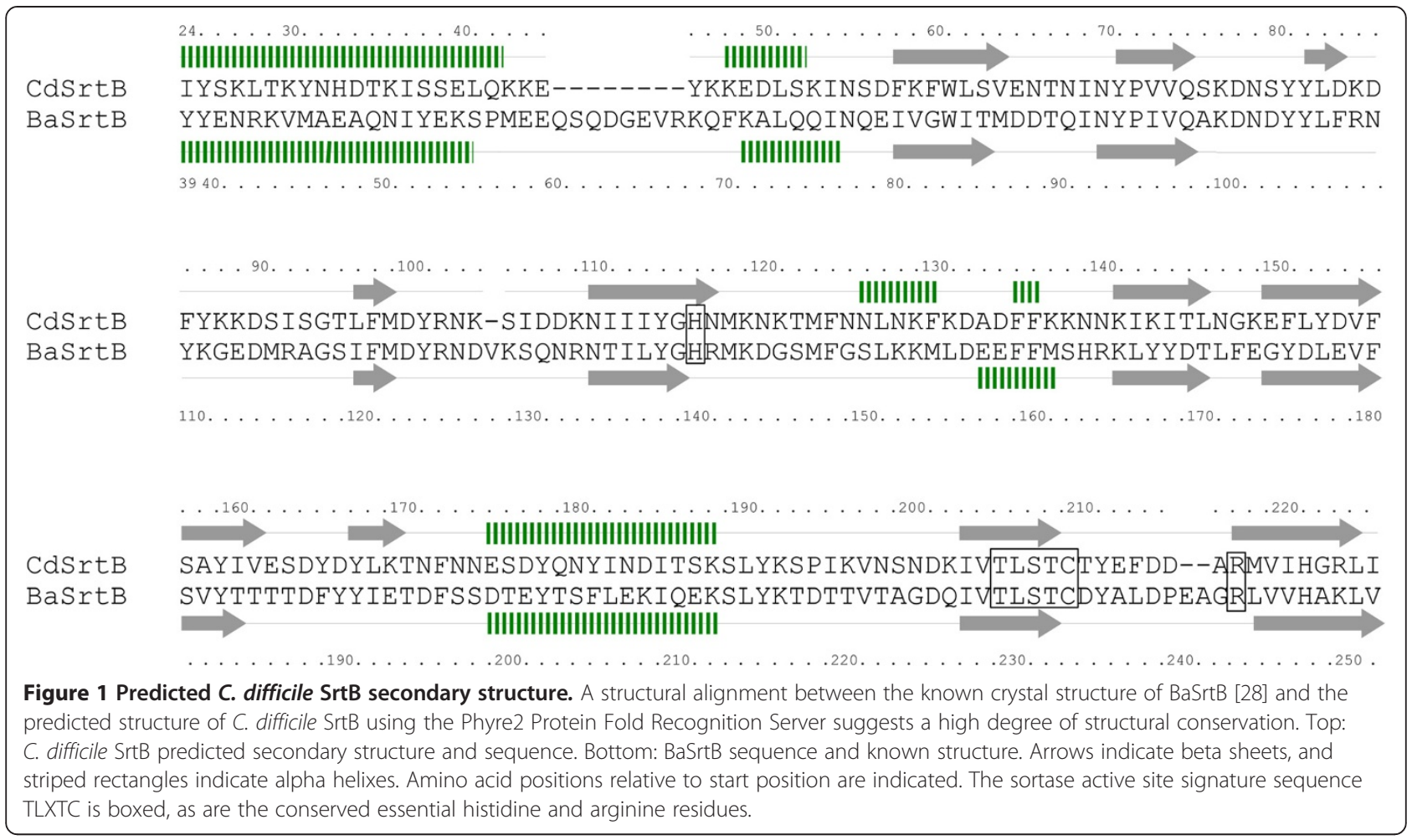

and at least two consecutive basic residues (arginine or lysine) at the C-terminus [31-33].

Eight proteins satisfied our definition of a sortase substrate in strain 630 (Table 1). The newly described $C$. difficile collagen binding protein $\mathrm{A}, \mathrm{CbpA}$, is the only protein containing the proposed NVQTG motif [30]. The remaining proteins contained one of four observed variations of the (S/P)PXTG motif: SPKTG, PPKTG, and SPSTG and SPQTG. These predicted $C$. difficile sortase substrates are a diverse range of surface proteins that include putative cell wall hydrolases, putative adhesins, a collagen-binding protein, and a 5' nucleotidase/phosphoesterase (Table 1). Transcriptional analysis performed by RT-PCR confirmed that all eight predicted substrate proteins are transcribed during growth in vitro (Additional file 1: Figure S1B-I). The eight predicted substrates are transcribed during all three growth phases examined, with the exception of CD630_25370 and CD630_32460, which do not appear to be transcribed during stationary phase. Four of these putative substrates are conserved across all five $C$. difficile lineages: CD630 01830, CD630_25370, CD630_27680, and CD630_28310.

\section{Purified C. difficile SrtB cleaves (S/P)PXTG peptides}

To determine whether $C$. difficile SrtB cleaves putative substrates at the predicted motifs, FRET peptides were designed based on the variations observed in the predicted (S/P)PXTG motif (Table 2). Two residues upstream of the

Table 1 Identification of putative C. difficile SrtB substrates in strain 630

\begin{tabular}{lll}
\hline Protein & Function & C-terminal sorting signal \\
\hline CD630_01830 & Putative cell wall hydrolase & MIHSPSTGKTVSVTSINSSYYYTARFVTAKRIL \\
CD630_03860 & Putative cell surface protein, collagen binding protein & PSDSPKTGDNTNLYGLLALLLTSG $\boldsymbol{A G L A G I F F Y K R R K M K K S ~}$ \\
CD630_25370 & Putative membrane-associated 5'-nucleotidase/phosphoesterase & KEKSPKTGDLGFSNSIIIFIVSSTLICLLNFNQKELKDKKSK \\
CD630_27680 & Putative cell-wall hydrolase & FIHSPQTGDVVKVTSMAPGTNYARRLITATRVLQ \\
CD630_28310 & Putative adhesion, collagen binding protein & PPVPPKTGDSTTIIGEILLVIGAIVGLIVLRRNKNTN \\
CD630_31450 & Collagen binding protein, CbpA & VGQNVQTGDQSNIMLDLALMFISLFFLIKNLTNKYLRRK \\
CD630_32460 & Putative surface protein & IVKSPKTGDETQLMSYVFISVIAICGLAYYQCKIKRN \\
CD630_33920 & Putative cell surface protein, collagen binding protein & PSDSPKTGDSTNLMAFIVMLLVSGGGLAGTYLYKRRKMKKS \\
\hline
\end{tabular}


Table 2 FRET peptide details

\begin{tabular}{ll}
\hline Peptide sequence* & Description \\
\hline$d$-IHSPSTGGG-e & Based on CD0183 sequence \\
$d$-IHGSSTPGG-e & Control for above peptide \\
$d$-SDSPKTGGG-e & Based on CD0386, CD3392 sequence \\
$d$-SDGSKTPGG-e & Control for above peptide \\
$d$-IHSPQTGGG-e & Based on CD2768 sequence \\
$d$-IHGSQTPGG-e & Control for above peptide \\
$d$-PVPPKTGGG-e & Based on CD2831 sequence \\
$d$-PVGPKTPGG-e & Control for above peptide \\
$d$-GQNVQTGGG-e & Based on CbpA sequence \\
$d$-QALPETGGG-e & SaSrtA peptide \\
$d$-NPQTN-e & SaSrtB peptide \\
$d$-IHSPSTGKT-e & Based on CD0183 sequence \\
$d$-SDSPKTGDN-e & Based on CD0386 sequence \\
$d$-IHSPQTGDV-e & Based on CD2768 sequence \\
$d$-PVPPKTGDS-e & Based on CD2831 sequence \\
\hline
\end{tabular}

*Where $d$ is Dabcyl (4-([4-(dimethylamino)phenyl]azo)-benzoyl) and $e$ is Edans (5-((2-Aminoethyl)amino)naphthalene-1-sulfonic acid).

motif were included, and two glycine residues were incorporated downstream, as this has been previously shown to improve sortase cleavage efficiency in vitro [34]. Fluorescence of the Edans fluorophore within the peptides is blocked when in close proximity to the fluorescent quencher Dabcyl [35]. When the peptide is cleaved, the Edans fluorophore is separated from Dabcyl, and a fluorescent signal is observed.

The N-terminal transmembrane domain of $C$. difficile SrtB (residues 2-25) was replaced with a six-histidine tag $\left(\mathrm{SrtB}_{\Delta \mathrm{N} 26}\right)$ to improve soluble protein yield. $\mathrm{SrtB}_{\Delta \mathrm{N} 26}$ was expressed in E. coli NiCo21(DE3) and purified by nickel affinity chromatography from cleared lysates (Figure 2). Purified $\mathrm{SrtB}_{\Delta \mathrm{N} 26}$ was then incubated with a
FRET peptide containing the SPKTG sequence. An increase in fluorescence was observed over time, indicating that cleavage of the SPKTG peptide occurred in the presence of $\mathrm{SrtB}_{\triangle \mathrm{N} 26}$ over 48 hours (Figure 3). In addition to the SPKTG motif, $\mathrm{SrtB}_{\triangle \mathrm{N} 26}$ also cleaved peptides containing the predicted substrate sequences PPKTG, SPSTG, and SPQTG (Figure 4). $\mathrm{SrtB}_{\triangle \mathrm{N} 26}$ failed to cleave the scrambled peptide sequences GSKTP, GPKTP, GSSTP and GSQTP (Figure 4). Interestingly, $\mathrm{SrtB}_{\triangle \mathrm{N} 26}$ failed to cleave peptides containing the LPETG and NPQTN motifs of SaSrtA and SaSrtB, respectively, and also failed to cleave the proposed sortase recognition motif NVQTG found in the $C$. difficile collagen binding protein, CbpA [30] (Figure 4).

\section{Analysis of FRET reaction}

To investigate the importance of the cysteine residue in the proposed active site of $C$. difficile SrtB, site-directed mutagenesis was used to replace the cysteine residue at position 209 with an alanine. When the resulting mutant protein $\mathrm{SrtB}_{\triangle \mathrm{N} 26, \mathrm{C} 209 \mathrm{~A}}$ was incubated with the FRET peptides, the fluorescent signal fell below the limits of detection (Figure 5), indicating that the cysteine residue at position 209 was essential for the activity of the $C$. difficile SrtB. Cleavage in the FRET-based assay was also inhibited by the addition of MTSET (Figure 5), a known cysteine protease inhibitor and inhibitor of sortase function in S. aureus [36,37] and B. anthracis [15].

The cleavage of the SPKTG, PPKTG, and SPQTG motifs was enhanced at least two-fold by the addition of the two native amino acids immediately downstream of this sequon (data not shown). Analysis of the FRET reaction with these modified peptides revealed that $\mathrm{SrtB}_{\triangle \mathrm{N} 26}$, cleaves these peptides between the T and G residues. MALDI analysis of $d$-PVPPKTGDS-e peptide incubated with $\mathrm{SrtB}_{\Delta \mathrm{N} 26}$ results in a peptide with a mass of $889 \mathrm{Da}$,

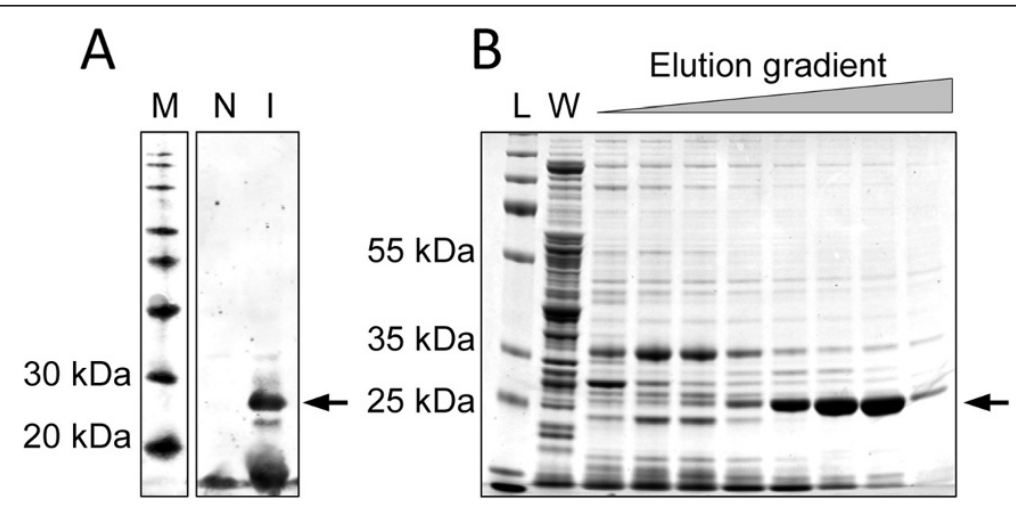

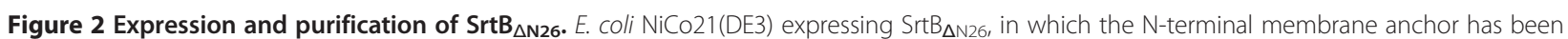
replaced with a six-histidine tag, were lysed by sonication and cleared lysates purified by nickel affinity chromatography. A. Anti-his western testing for expression of $\mathrm{SrtB}_{\Delta \mathrm{N} 26}$. Lane M: molecular mass marker, $\mathrm{N}$ : whole cell lysate of non-induced culture, I: whole cell lysate of culture induced with $1 \mathrm{mM}$ IPTG. B. Coomassie-stained SDS-PAGE analysis of SrtB ${ }_{\Delta \mathrm{N} 26}$ purification over an imidazole gradient. Lane L: molecular mass marker, W: column wash, imidazole gradient indicated by grey triangle, arrows indicate the $\mathrm{SrtB}_{\Delta \mathrm{N} 26}$ protein. 


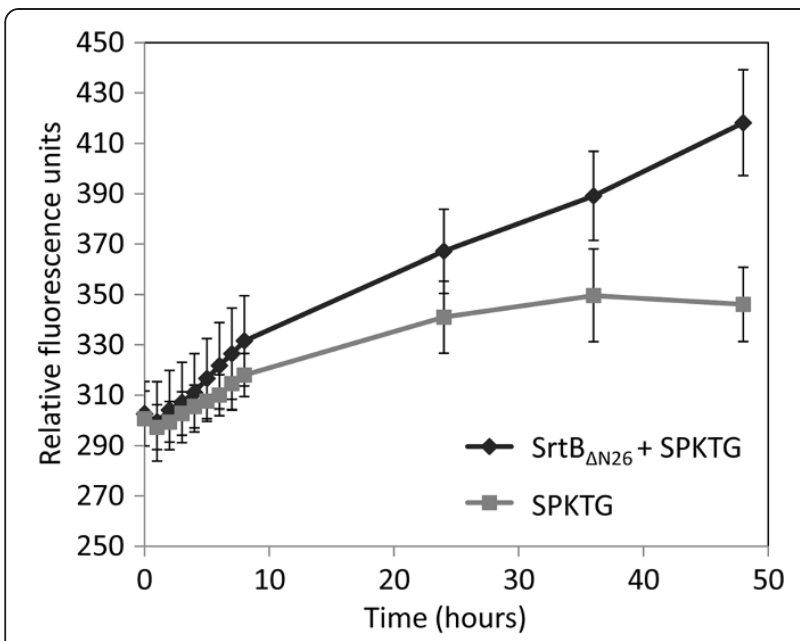

Figure 3 Cleavage of SPKTG peptide by recombinant $\mathrm{SrtB}_{\triangle \mathrm{N} 26}$. Purified recombinant $\mathrm{SrtB}_{\triangle \mathrm{N} 26}$ was incubated with a FRET peptide containing the SPKTG motif and fluorescence measured every hour for the first eight hours, and also at 24 h, 36 h, and 48 h. An increase in relative fluorescence units (arbitrary units) was observed, compared with the peptide incubated alone, indicating that $\mathrm{SrtB}_{\Delta \mathrm{N} 26}$ mediated cleavage of the SPKTG peptide occurred over a period of 48 hours. Error bars represent the standard error of the mean.

corresponding to the fragment $d$-PVPPKT-OH (Figure 6, top). The peptide control, incubated without $\mathrm{SrtB}_{\Delta \mathrm{N} 26 \text {, }}$ lacked this fragment (Figure 6, bottom). Cleavage between the $\mathrm{T}$ and $\mathrm{G}$ residues for the $d$-SDSPKTGDN-e and $d$ IHSPQTGDV-e peptides was also confirmed (data not shown), indicating that $C$. difficile SrtB cleaves the $(\mathrm{S} / \mathrm{P})$ PXTG motif between the same residues as other functional sortases $[4,15,38,39]$.

\section{Kinetic measurements of SrtB activity}

In order to calculate the in vitro kinetic parameters of $\mathrm{SrtB}_{\triangle \mathrm{N} 26}$ for the $d$-SDSPKTGDN-e and $d$-PVPPKTGDS-e peptides, we performed a kinetic analysis of the sortase- catalyzed hydrolysis reaction. Figure 7A shows the progress curves of the $\mathrm{SrtB}_{\Delta \mathrm{N} 26}$ catalyzed hydrolysis reactions at various $d$-SDSPKTGDN-e concentrations. For each progress curve, the amount of fluorescent product (after conversion from RFU to concentration) was approximately $5 \%$ of the initial substrate concentration. Within the time period analyzed, the progress curves are linear, so the steady state rate $(V)$ was determined by fitting the data to a linear function. Figure $7 \mathrm{~B}$ shows $V$ plotted against the concentration of the peptide. Non-linear regression of these data fitted to a modified Michaelis-Menten equation incorporating substrate inhibition (Equation 1):

$$
V=\frac{V_{\max } \cdot[S]}{K_{m}+[S]+\frac{[S]^{2}}{K_{i}}}
$$

Using SciPy 0.11.0 in Python 2.7.3, where $V_{\max }$ is the apparent maximal enzymatic velocity, $K_{m}$ is the apparent Michaelis constant, and $K_{i}$ is the apparent inhibitor dissociation constant for unproductive substrate binding. This resulted in a $K_{m}$ of $74.7 \pm 48.2 \mu \mathrm{M}$ and a $K_{\text {cat }}$ of $1.1 \times 10^{-3} \pm 6 \times 10^{-4} \mathrm{~min}^{-1}$ for $d$-SDSPKTGDN-e (Figure 7B). This analysis was performed for $d$-PVPPKTGDS-e, resulting in a $K_{m}$ of $53.3 \pm 25.6 \mu \mathrm{M}$ and a $K_{\text {cat }}$ of $8.3 \times 10^{-4} \pm$ $3 \times 10^{-4} \mathrm{~min}^{-1}$. SrtB ${ }_{\Delta \mathrm{N} 26}$ is subject to substrate inhibition; at peptide concentrations greater than $30 \mu \mathrm{M}$, the rate of $\mathrm{SrtB}_{\triangle \mathrm{N} 26}$ activity decreases. Substrate inhibition has previously been observed for other sortase enzymes in vitro, and is not expected to be physiologically relevant [40].

\section{Inhibiting SrtB activity}

We sought to determine whether $C$. difficile SrtB could be specifically targeted using small-molecule inhibitors. The published crystal structure of the B. anthracis SrtB (BaSrtB) [28] was used as a template for the selection of potential $C$. difficile SrtB inhibitors. These orthologous proteins show $70 \%$ identity and $90 \%$ similarity at the active

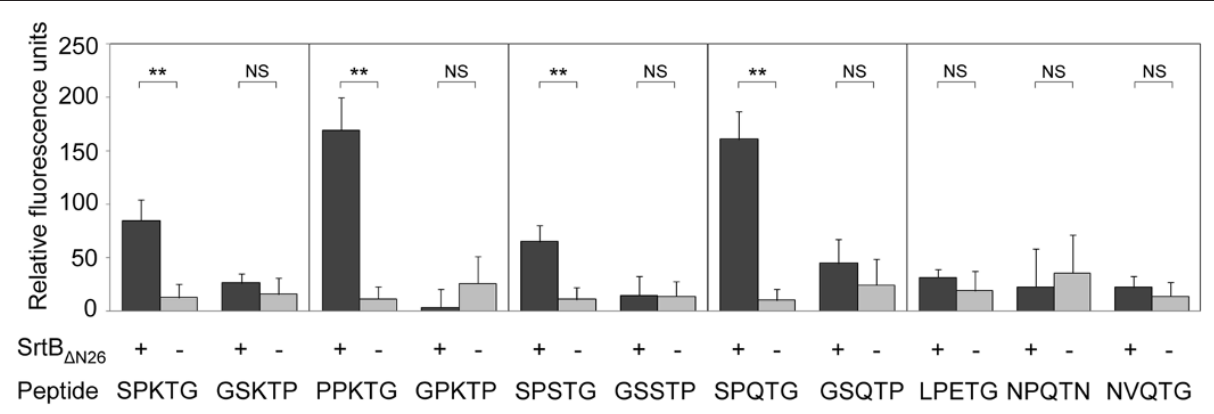

Figure $4 \mathrm{SrtB}_{\triangle \mathbf{N} 26}$ substrate specificity. Purified recombinant SrtB ${ }_{\triangle N 26}$ protein was incubated with a range of peptide sequences to investigate its substrate specificity. The motifs SPKTG, PPKTG, SPSTG and SPQTG were all recognized and cleaved following incubation with SrtB $\Delta$ N26. The scrambled peptide sequences GSKTP, GPKTG, GSSTP, and GSQTP serve as controls for the cleavage specificity of SrtB $\Delta$ N26. The sequences LPETG and NPQTN, corresponding to the motifs recognized by S. aureus sortase A and B, respectively, do not appear to be substrates for SrtB $\Delta$ N26. $\mathrm{SrtB}_{\triangle N 26}$ also failed to cleave the proposed sorting signal NVQTG from recently characterized collagen binding protein, CbpA. Bars indicate the mean, and error bars represent the standard error (** corresponds to $p<0.01$ ). 
site, and their differences are confined to the periphery of the active site. The proprietary LeadBuilder virtualscreening method (Domainex Ltd) was used to interrogate the PROTOCATS database of potential protease inhibitors with pharmacophoric and docking filters derived from analysis of the BaSrtB crystal structure. PROTOCATS comprises 80,000 commercially-available compounds that may form reversible transition-state-like complexes with protease enzymes. Compounds in PROTOCATS contain a carbonyl group which is activated to make a fully reversible complex with the active-site serine/cysteine group by virtue of adjacent moderately electron-withdrawing substituents, which are not leaving groups. Some examples of these functional groups are $\alpha$-ketoamides and aryl ketones. Figure 8A shows one of the identified compounds docking within the active site structure of BaSrtB.

Compounds identified in this screen as potential SrtB inhibitors were tested alongside the cysteine protease inhibitor MTSET at a range of concentrations in the FRET-based assay using the $d$-PVPPKTGDS-e peptide to compare IC50 values. Addition of MTSET reduced $\mathrm{SrtB}_{\triangle \mathrm{N} 26}$ activity to below the limits of detection at concentrations of $500 \mu \mathrm{M}$ and greater. MTSET exhibited an IC50 of $286.7 \pm 16.6 \mu \mathrm{M}$ (Figure $8 \mathrm{~B}$ ). A panel of potential $C$. difficile SrtB inhibitors were screened for inhibition of $\mathrm{SrtB}_{\Delta \mathrm{N} 26}$ activity. The most effective of the 62 compounds were LSHTM40, LSHTM50, and LSHTM52. They had IC50 values below $100 \mu \mathrm{M}$ (Figure 8B, Table 3), at $63.1 \pm 8.8 \mu \mathrm{M}, 60.1 \pm 4.7 \mu \mathrm{M}$, and $44.1 \pm 6.9 \mu \mathrm{M}$, respectively, showing a good efficacy against $C$. difficile $\mathrm{SrtB}$ activity.

\section{Discussion}

C. difficile infection is invariably associated with the disruption of the normal intestinal microflora by the administration of broad spectrum antibiotics. Thus there is a pressing need to develop therapies that selectively target $C$. difficile while leaving the intestinal microflora intact. The $C$. difficile reference strain 630 encodes a single predicted sortase, CD630_27180, which has strong amino acid similarity with SrtB of $S$. aureus and B. anthracis [24]. Sortase substrates frequently contribute toward pathogenesis via their involvement in attachment to specific tissues during infection $[17,41-44]$, as well as the bacteria's ability to evade the immune response of the host [32,36]. Sortases, although not essential for growth or viability of the organism, are often essential for virulence in Gram-positive organisms; inactivation of sortases reduces colonization in mice $[8,13,44,45]$, and decreases adhesion and invasion in vitro $[8,10,14,46,47]$. Sortases and their substrates are considered promising targets for the development of new anti-infective compounds $[10,14,48]$. Unusually for Gram-positive bacteria, C. difficile appears to possess a single sortase enzyme that is likely to be important for the viability of the pathogen as we have been unable to construct a $C$. difficile strain 630 SrtB defined mutant (unpublished data). Inhibiting the $C$. difficile sortase could prove to be a strategy to specifically target $C$. difficile.

In this study, we cloned, expressed and characterized the sortase encoded by CD630_27180 of C. difficile 630, a predicted class B sortase (SrtB). Sortase nomenclature is based on sequence similarity to the known classes of sortase, A-F [7]. Sortases of class B typically are involved in heme-iron uptake and tend to be expressed in operons with their substrates [17,18]. Genes encoding class A sortases are not found in proximity to their substrates, which consist of a variety of surface proteins with diverse biological functions. Several exceptions to these rules have already been described, notably a class B sortase that polymerizes pilin subunits in S. pyogenes [49], and a class $\mathrm{E}$ sortase from $C$. diphtheriae that serves a housekeeping function [50]. The potential $C$. difficile sortase substrates identified in this paper comprise a diverse 


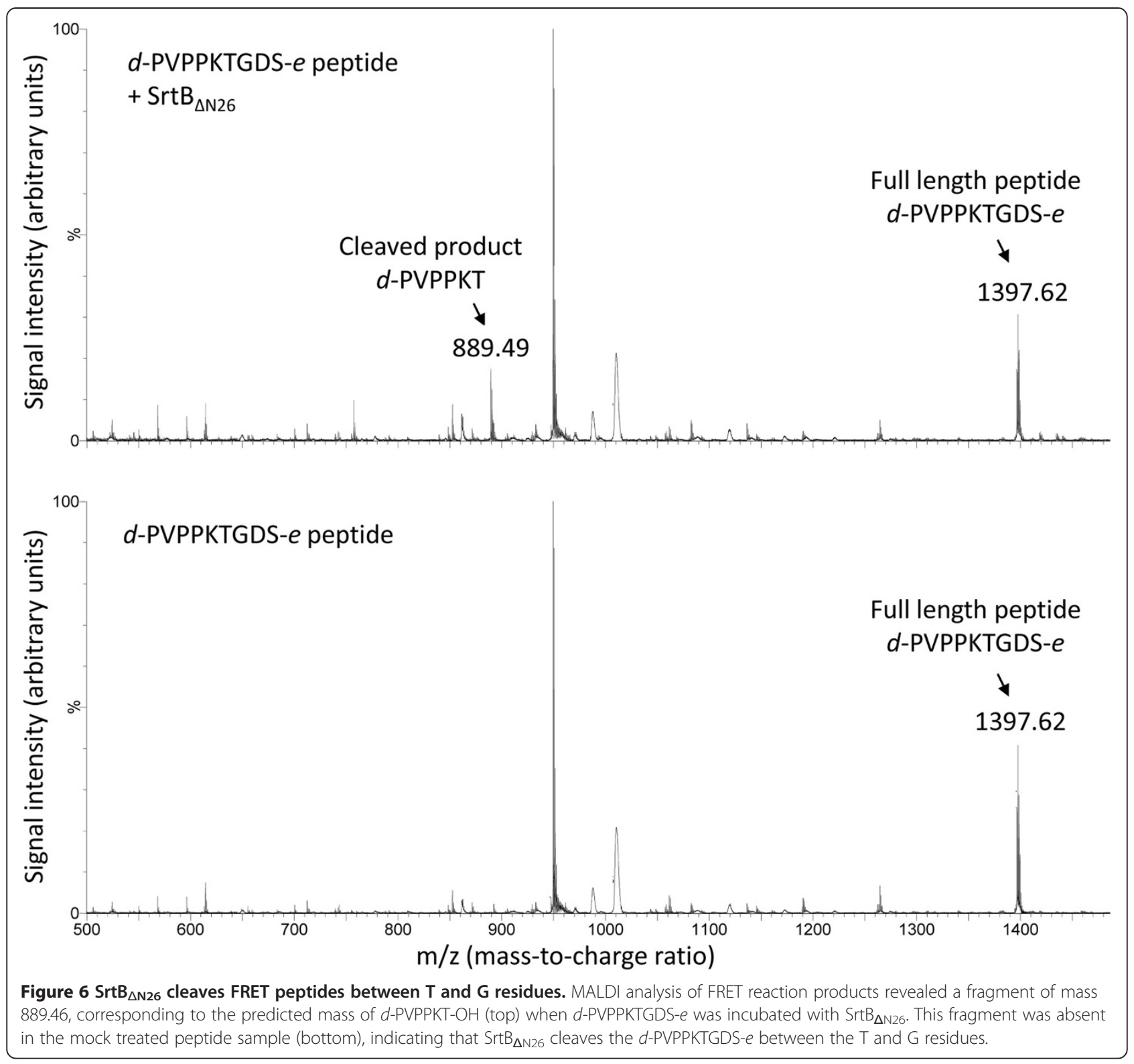

range of surface proteins, suggesting that SrtB may serve as a housekeeping sortase in $C$. difficile, a function usually reserved for class A sortases.

These potential sortase substrates in $C$. difficile strain 630 comprise of seven proteins, all containing an (S/P) PXTG motif, that are predicted to be surface localized and are conserved across $C$. difficile strains. Recently it was proposed that a $C$. difficile collagen binding protein, CbpA, may be sorted to the cell surface by sortase recognizing an NVQTG motif [30]. In this study, we developed a FRET-based assay to demonstrate that SrtB of $C$. difficile recognizes and cleaves the (S/P)PXTG motif between the threonine and glycine residues, and that cleavage is dependent on a single cysteine residue at position 209. $\mathrm{SrtB}_{\Delta \mathrm{N} 26}$ does not appear to cleave the $S$. aureus
SrtA and SrtB motifs, LPXTG and NPQTN, respectively, nor the NVQTG motif in vitro, suggesting that CbpA from $C$. difficile may be attached to the cell surface by another mechanism.

The FRET-based assay enabled us to determine kinetic parameters for the recombinant C. difficile SrtB. Although the catalytic activity appears low, low catalytic efficiency is observed for most sortases in vitro [40,51]. The kinetic and cleavage data we report for $\mathrm{SrtB}_{\Delta \mathrm{N} 26}$ is consistent with this trend. In vivo, the sorting motifs are part of a larger protein, and the transpeptidation substrates are part of a cell wall precursor or mature peptidoglycan $[5,6,39]$. The transpeptidation reaction has been observed in vitro for sortases from bacteria with a Lys-type peptidoglycan, where cross-linking occurs through a peptide 

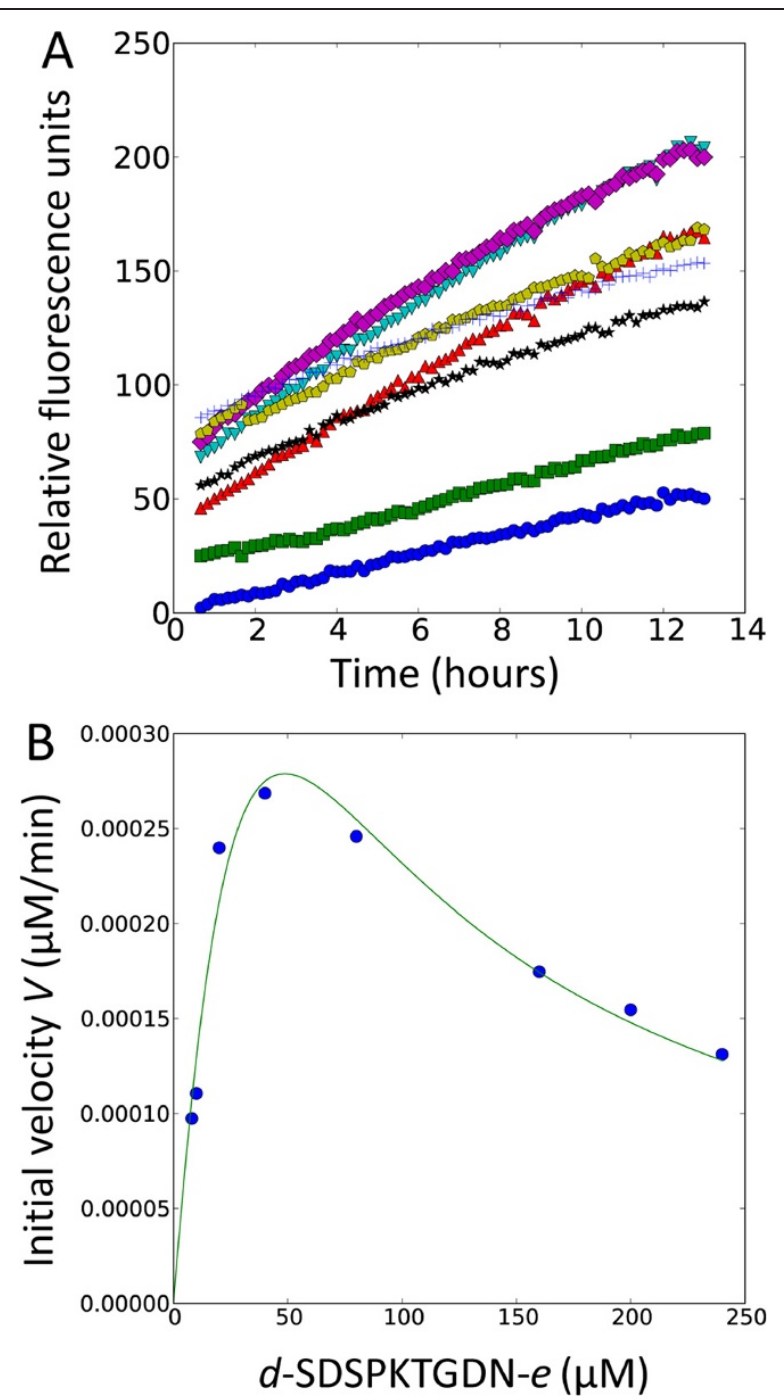

Figure 7 Kinetic parameters of $\mathrm{SrtB}_{\triangle \mathrm{N} 26}$. In order to determine the in vitro kinetic parameters of $\mathrm{SrtB}_{\triangle \mathrm{N} 26}$ for the SPKTG and PPKTG motifs, we performed a kinetic analysis of the sortase-catalyzed hydrolysis reaction. A. Progress curves of the $\mathrm{SrtB}_{\triangle \mathrm{N} 26}$-catalyzed hydrolysis reactions at various concentrations of $d$-SDSPKTGDN-e [8 (blue $\bullet$ ), 10 (green $\bullet$ ), 20 (red $\boldsymbol{\Lambda}$ ), 40 (teal $\mathbf{\nabla}$ ), 80 (purple $\bullet$ ), 160 (yellow ), 200 (black $\star$ ), and $240 \mu \mathrm{M}$ (blue +). The steady state rate $(V)$ was determined by fitting the data to a linear function. B. Plot of $V$ against the concentration of the peptide [S]. Nonlinear regression of these data fitted to Equation 1 resulted in a $K_{m}$ of $74.7 \pm 48.2 \mu \mathrm{M}$ for $d$-SDSPKTGDN-e. SrtB ${ }_{\triangle N} 26$ is subject to substrate inhibition at peptide concentrations $>30 \mu \mathrm{M}$, which is not expected to be physiologically relevant.

bridge [52,53] such as S. aureus and Streptococcus species $[4,40,54]$, but not for bacteria with Dap-type peptidoglycan such as Bacillus with direct cross-linkages through $m$ diaminopimelic acid [55]. The likely cell wall anchor of the C. difficile SrtB substrates is the diaminopimelic acid cross-link [56], similar to Bacillus. When transpeptidation is observed in vitro, the cleavage efficiency of sortase increases.
This study revealed that recombinant $\mathrm{SrtB}_{\Delta \mathrm{N} 26}$ cleaves the (S/P)PXTG motifs with varying levels of efficiency, cleaving the sequences PPKTG and SPQTG with the greatest efficiency. Apparent preferential cleavage efficiency of certain substrate sequences in vitro has been observed in other sortases. For example, in B. anthracis, BaSrtA cleaves LPXTG peptides more readily than a peptide containing the sequence LPNTA [15]. The biological significance of this peptide sequence preference is unknown.

Small-molecule inhibitors with activity against SrtA and SrtB have been reported that prevent cleavage of fluorescently-labelled peptide compounds by sortase in vitro [57]. These compounds inhibit cell adhesion to fibronectin, yet, they have no effect on in vitro growth. Inhibitors tested against SrtA, SrtB and SrtC in B. anthracis irreversibly modified the active cysteine residue [58]. Several compounds identified in this study had an inhibitory effect on $C$. difficile SrtB activity. However, these lead compounds had no direct effect on in vitro $C$. difficile growth (data not shown), which is consistent with observations in S. aureus [57]. Inhibition of bacterial growth is not considered vital in the development of sortase-based drug therapies. In both Staphylococcus and Bacillus, sortase inhibitors show good suitability for further development as therapeutics despite their lack of bactericidal activity. When mice challenged with $S$. aureus were treated with sortase inhibitor compounds, infection rates and mortality were reduced [59], despite these compounds having no effect on staphylococcal growth [57]. The use of in silico approaches such as the LeadBuilder method employed by this study to screen databases of putative small-molecule inhibitors for further analysis has been validated. Further analysis of the structural similarities between the hit compounds could lead to a refinement of SrtB inhibitor design and increased potency in vitro.

\section{Conclusions}

In conclusion, we demonstrate that $C$. difficile encodes a single sortase, $\mathrm{SrtB}$, with in vitro activity. We have confirmed the $C$. difficile SrtB recognition sequence as (S/P)PXTG, and show that $C$. difficile SrtB cleaves the (S/P)PXTG motif within peptides between the threonine and glycine residues. The cysteine residue within the predicted active site is essential for activity of the enzyme, and the cleavage of fluorescently-labelled peptides can be inhibited by MTSET, a known cysteine protease inhibitor. SrtB inhibitors identified through our in silico screen show a greater level of efficacy then MTSET at inhibiting the protease activity of $C$. difficile SrtB. Such inhibitors provide a significant step in successfully identifying C. difficile SrtB inhibitor compounds, which can be further refined to enhance their efficacy, and may 

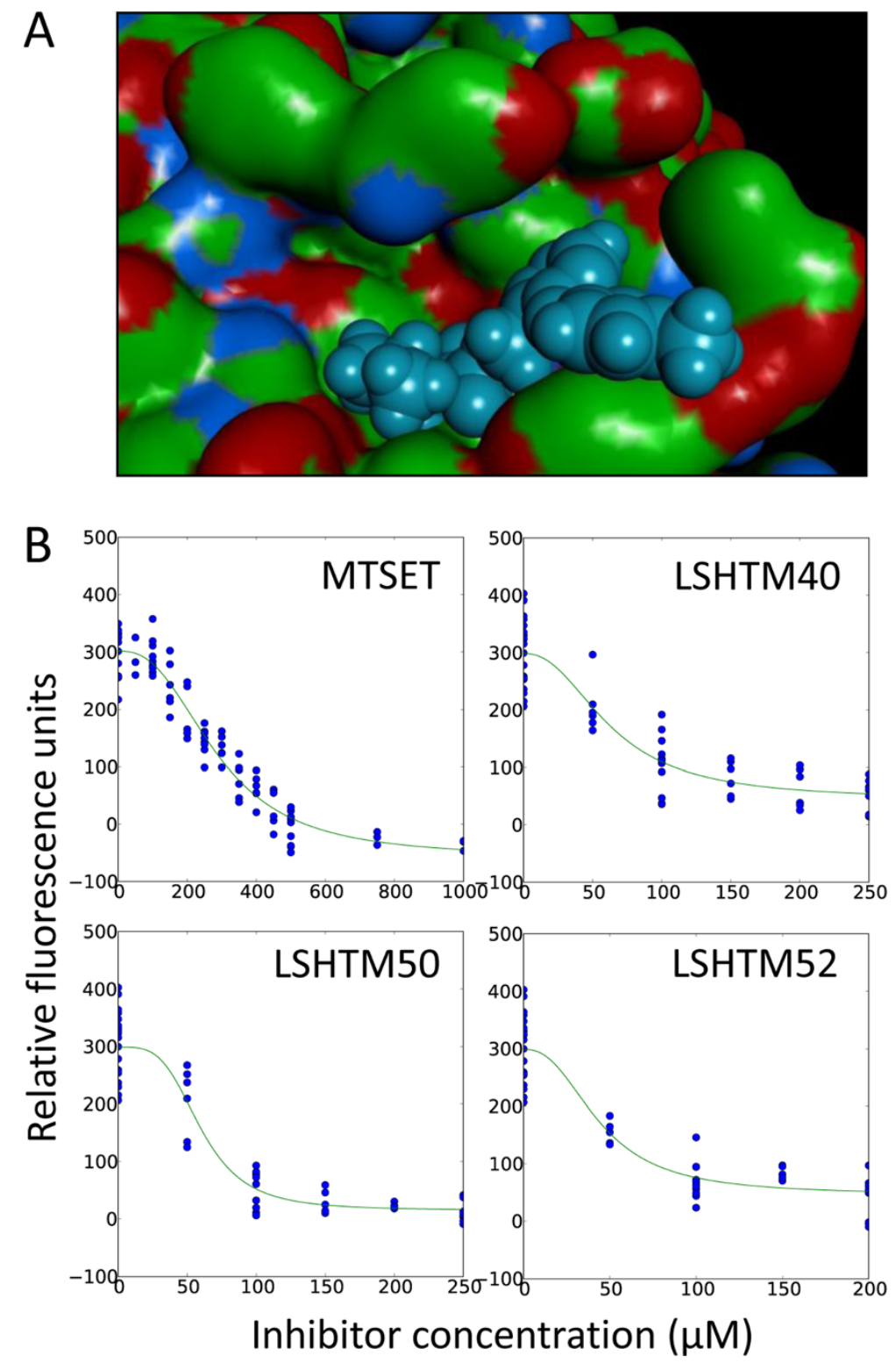

Figure $8 \mathrm{SrtB}_{\triangle \mathrm{N} 26}$ activity can be inhibited by rationally designed inhibitors. The proprietary LeadBuilder virtual-screening method (Domainex Ltd) was used to screen a database of 80,000 potential protease inhibitors, PROTOCATS, with pharmacophoric and docking filters derived from analysis of the BaSrtB crystal structure [28]. A. Space filling model showing one of the hit compounds fitting into the active site of BaSrtB and interacting with the catalytic cysteine residue. B. MTSET and the hits from the virtual screen were tested in the FRET-based assay at varying concentrations to screen for inhibition of $\mathrm{SrtB}_{\triangle \mathrm{N} 26}$ mediated cleavage of $d$-PVPPKTGDS-e. The most effective compounds were LSHTM40, LSHTM50, and LSHTM52, which had IC50 values of $63.1 \pm 8.8,60.1 \pm 4.7$ and $44.1 \pm 6.9 \mu \mathrm{M}$, respectively. The IC50 for MTSET was $286.7 \pm 16.6 \mu \mathrm{M}$, indicating its inhibitory effect on $\mathrm{SrtB}_{\triangle \mathrm{N} 26}$ is less potent than the three identified compounds.

contribute towards the development of novel selective therapeutics against CDI.

\section{Methods}

\section{Bacterial culture}

C. difficile strain 630 [24] was cultured on Brazier's agar (BioConnections) supplemented with $4 \%$ egg yolk (BioConnections) and 1\% defibrinated horse blood (TCS Biosciences Ltd.). Liquid cultures were grown in brain heart infusion broth (Oxoid Ltd.) supplemented with $0.05 \%$ L-cysteine (BHIS broth). All media was supplemented with $C$. difficile antibiotic supplement $(250 \mu \mathrm{g} / \mathrm{ml}$ D-cycloserine and $8 \mu \mathrm{g} / \mathrm{ml}$ cefoxitin, BioConnections). $C$. difficile cultures were incubated at $37^{\circ} \mathrm{C}$ for $24-48$ hours in a Whitley MG500 anaerobic workstation (Don Whitley Scientific Ltd.).

One Shot Top $10^{\circ}$ (Invitrogen) and XL-1 Blue (Agilent) Escherichia coli were used for all cloning steps, and 
Table 3 Structure of most effective inhibitors of SrtB ${ }_{\Delta N 26}$

\begin{tabular}{lll}
\hline Compound & Structure & IC50 \\
\hline LSHTM-0040 & $63.1 \pm 8.8 \mu \mathrm{M}$
\end{tabular}

LSHTM-0050

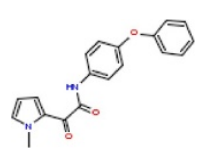

LSHTM-0052

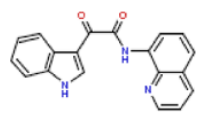

NiCo21(DE3) E. coli (NEB) was used for the expression of recombinant proteins [60]. E. coli strains were grown at $37^{\circ} \mathrm{C}$ on Luria-Bertani (LB) agar (Novagen) or in LB broth (Difco). Media was supplemented with $100 \mu \mathrm{g} / \mathrm{ml}$ ampicillin or $50 \mu \mathrm{g} / \mathrm{ml}$ kanamycin as required.

\section{Genomic DNA isolation}

Genomic DNA was isolated from C. difficile strain 630 $[24,61]$ by phenol chloroform extraction as previously described [29] and used as a template for cloning. The annotated genome sequences from $C$. difficile strains R20291 and CD196 (RT027) [29], M68 and CF5 (RT017) [20], M120 (RT078) [20], and CD305 (RT023) (unpublished, Wellcome Trust Sanger Institute) were used for analysis.

\section{Identification of sortase substrates}

All proteins encoded by $C$. difficile strain 630 [24,61] were searched for the patterns (S/P)PXTG [11] and NVQTG [30] positioned 17-45 amino acid residues from the C-terminus [31]. The resulting candidate protein list was assessed for the known features of a sortase substrate: (i) a suitable $\mathrm{N}$-terminal signal peptide sequence, as predicted by SignalP 4.1 Server (http://www. cbs.dtu.dk/services/SignalP/) [62], (ii) a potential transmembrane segment following the C-terminal "LPXTGlike" sequence, as predicted by TMHMM Server v. 2.0 (http://www.cbs.dtu.dk/services/TMHMM/) [63], and (iii) at least two consecutive basic residues (arginine or lysine) at the C-terminus [31-33].

\section{Genetic manipulation}

A list of primers and plasmids used in this study can be found in Tables 4 and 5, respectively. The coding
Table 4 Primers used in this study

\begin{tabular}{ll}
\hline Primer & Sequence \\
\hline PET_3 & gatattccatggatgaagaaactgtaccgtatcgttatc \\
PET_4 & gatgagctcgaggatcagacgaccgtggataacc \\
PET_17 & $\begin{array}{l}\text { gatataccatggatgcaccaccaccaccaccactctaaactgaccaaata } \\
\text { caaccacgacac }\end{array}$ \\
PET_16 & gatgagctcgagttagatcagacgaccgtggataac \\
C209A & tcgttaccctgtctaccgccactacgaattcgacg \\
C209A_antisense & cgtcgaattcgtaggtggcggtagacagggtaacga \\
T7F & taatacgactcactataggg \\
T7R & gctagttattgctcagcgg \\
\hline
\end{tabular}

sequence for srtB (CD630_27180) was codon-optimized for expression in $E$. coli by Celtek Bioscience, LLC (Nashville, TN, USA). The resulting fragment was cloned into the NcoI/XhoI sites of pET28a using primers pET_3 and pET_4 to create pET28a-srtB. To improve soluble SrtB yield, the N-terminal transmembrane anchor domain (residues 2-25) was replaced with a six-histidine tag. The truncated gene $s r t B_{\Delta \mathrm{N} 26}$ was amplified from pET28a-srtB using primers pET_17 and pET_16, and cloned into the NcoI/XhoI sites of pET28a to create pET28a-srt $B_{\triangle \mathrm{N} 26}$. The mutant protein $\mathrm{SrtB}_{\triangle \mathrm{N} 26, \mathrm{C} 209 \mathrm{~A}}$ was generated using the QuikChange Site-Directed Mutagenesis kit (Agilent) in accordance with the manufacturer's instructions using pET28a-srtB $B_{\triangle \mathrm{N} 26}$ as a template and primers C209A and C209A_antisense. Successful construction of recombinant plasmids was confirmed by DNA sequencing using primers T7F and T7R (Source BioScience).

\section{RT-PCR analysis}

Total RNA was isolated from $C$. difficile 630 grown in BHIS at early exponential phase $\left(\mathrm{t}=3\right.$ hours, $\mathrm{OD}_{600}=$ 0.4-0.5), late exponential phase $\left(t=5\right.$ hours, $\mathrm{OD}_{600}=0.8$ $0.9)$, and stationary phase $\left(\mathrm{t}=24\right.$ hours, $\left.\mathrm{OD}_{600}=0.6-0.8\right)$ using RNAprotect Bacteria Reagent (Qiagen) and the FastRNA Pro Blue Kit (MP Biomedicals LLC., Illkirch,

Table 5 Plasmids used in this study

\begin{tabular}{|c|c|c|}
\hline Plasmid & Description & Reference \\
\hline pQE30Xa- srtB & $\begin{array}{l}\text { Codon optimized srtB, } \\
\text { synthesized and cloned } \\
\text { in pQE30xa }\end{array}$ & $\begin{array}{l}\text { Obtained from } \\
\text { Celtek Bioscience, } \\
\text { LLC }\end{array}$ \\
\hline pET28a & $\begin{array}{l}\text { Commercial protein } \\
\text { expression vector }\end{array}$ & $\begin{array}{l}\text { Provided by } \\
\text { Neil Fairweather }\end{array}$ \\
\hline pET28a- srtB & $\begin{array}{l}\text { Codon optimized srtB } \\
\text { cloned in pET28a }\end{array}$ & This work \\
\hline pET28a- $s r t B_{\Delta \mathrm{N} 26}$ & $\begin{array}{l}\text { srt } B \text { with residues 2-25 } \\
\text { replaced with a } \\
\text { six-histidine tag }\end{array}$ & This work \\
\hline pET28a- $s r t B_{\triangle N 26, C 209 A}$ & $\begin{array}{l}\text { Same as above, with } \\
\text { C209A substitution }\end{array}$ & This work \\
\hline
\end{tabular}


France) in accordance with the manufacturer's instructions. Genomic DNA was removed from total RNA samples using TURBO DNase (Life Technologies). Equal amounts of RNA were reverse transcribed into complementary DNA (cDNA) for expression analysis. Briefly, one $\mu \mathrm{g}$ random primers (Invitrogen) and 40 units $\mathrm{RNa}$ sin Plus RNase inhibitor (Promega) was added to one $\mu \mathrm{g}$ RNA in a final volume of $10 \mu \mathrm{l}$, and incubated at $65^{\circ} \mathrm{C}$ for $10 \mathrm{~min}$ followed by room temperature for $30 \mathrm{~min}$. The following first-strand mixture was added for cDNA synthesis: four $\mu \mathrm{l}$ of $5 \mathrm{x}$ first-strand buffer (Invitrogen), two $\mu \mathrm{l} 0.1 \mathrm{M}$ DTT (Invitrogen), two $\mu \mathrm{l} 10 \mathrm{mM}$ dNTP mix (New England BioLabs), and $1.5 \mu \mathrm{l}$ Superscript II (Invitrogen). The reaction mixture was incubated at $25^{\circ} \mathrm{C}$ for 10 minutes, $42^{\circ} \mathrm{C}$ for $1 \mathrm{~h}$, and finally $70^{\circ} \mathrm{C}$ for 15 minutes. RT-PCRs were performed with gene specific primers (Additional file 2: Table S1) using cDNA as a template.

\section{Purification of recombinant protein}

Expression constructs were transformed into $E$. coli $\mathrm{NiCo} 21(\mathrm{DE} 3)$ (NEB). Cultures grown at $37^{\circ} \mathrm{C}$ were induced for expression with $1 \mathrm{mM}$ IPTG when the $\mathrm{OD}_{600}$ reached 0.6, and harvested after 5 hours. Cell pellets were resuspended in lysis buffer [ $1 \times$ Bugbuster (Novagen), $50 \mathrm{mM} \mathrm{NaH} \mathrm{PO}_{4}, 300 \mathrm{mM} \mathrm{NaCl}, 40 \mathrm{mM}$ imidazole, $1 \mathrm{mM}$ DTT, $1 \mathrm{mg} / \mathrm{ml}$ lysozyme, and $25 \mathrm{U} / \mathrm{ml}$ Benzonase nuclease (Novagen) ( $\mathrm{pH}$ 7.5)]. Lysates were sonicated on ice for $2 \mathrm{~min}\left(15 \mathrm{sec}\right.$ on/off) at $50 \%$ Vibra Cell $^{\text {Tw }}$ high intensity ultrasonic processor (Jencon, Leighton Buzzard, Bedfordshire, UK) before centrifugation at 10,000 rpm for $45 \mathrm{~min}$. The supernatant was passed through a $0.22 \mu \mathrm{M}$ filter before applying to a $1 \mathrm{ml}$ HisTrap HP column (GE Healthcare), pre-equilibrated with buffer $(50 \mathrm{mM}$ $\mathrm{NaH}_{2} \mathrm{PO}_{4}, 300 \mathrm{mM} \mathrm{NaCl}, 40 \mathrm{mM}$ imidazole, $1 \mathrm{mM}$ DTT, $\mathrm{pH}$ 7.5). $\mathrm{SrtB}_{\triangle \mathrm{N} 26}$ was eluted with an imidazole gradient $(40-500 \mathrm{mM})$ over 25 column volumes. Fractions containing $\mathrm{SrtB}_{\triangle \mathrm{N} 26}$ (as identified by SDS-PAGE) were pooled and injected onto a HiLoad 16/60 Superdex 200 column (GE Healthcare) pre-equilibrated with buffer $\mathrm{F}(5 \mathrm{mM}$ $\mathrm{CaCl}_{2}, 50 \mathrm{mM}$ Tris- $\mathrm{HCl}$ (pH 7.5), $150 \mathrm{mM} \mathrm{NaCl}, 1 \mathrm{mM}$ DTT). Eluted fractions containing $\mathrm{SrtB}_{\triangle \mathrm{N} 26}$ were pooled and concentrated using an Amicon Ultra-15 (10 kDa) centrifuge filter unit (Millipore). Protein samples were quantified using Bradford reagent (Thermo Scientific) and analyzed by SDS-PAGE. The mutant protein $\mathrm{SrtB}_{\triangle \mathrm{N} 26, \mathrm{C} 209 \mathrm{~A}}$ was expressed and purified following the above method. Expression of $\mathrm{SrtB}_{\triangle \mathrm{N} 26}$ and $\mathrm{SrtB}_{\triangle \mathrm{N} 26, \mathrm{C} 209 \mathrm{~A}}$ was confirmed by MALDI fingerprinting.

\section{Immunoblotting}

Samples were resolved on Novex NuPage 10\% Bis-Tris SDS-PAGE gels (Invitrogen) before transferring to Hybond$\mathrm{C}$ Extra nitrocellulose (GE Healthcare). Membranes were probed with rabbit antiserum directed against 6xHis-tag (1:5000, Abcam), followed by goat anti-rabbit IRDye conjugated secondary antibody (1:7500, LI-COR Biotechnology). Blots were visualized using an Odyssey near-infrared imager (LI-COR Biotechnology).

\section{In vitro analysis of sortase activity}

$\mathrm{SrtB}_{\triangle \mathrm{N} 26}$ activity was monitored using a fluorescence resonance energy transfer (FRET) assay [58] in buffer $\mathrm{F}$ (5 mM CaCl $2,50 \mathrm{mM}$ Tris- $\mathrm{HCl}(\mathrm{pH} 7.5), 150 \mathrm{mM}$ $\mathrm{NaCl}$, and $1 \mathrm{mM} \mathrm{DTT})$. Fluorescently self-quenched peptides tagged with 5-((2-Aminoethyl)amino)naphthalene-1-sulfonic acid (Edans) as a fluorophore and 4-([4(Dimethylamino)phenyl]azo)benzoic acid (Dabcyl) as a quencher [35], and containing the predicted sorting signals of SrtB were purchased from Protein Peptide Research Ltd and solubilized in DMSO (Table 2). The FRET-based assay was performed in a final volume of $100 \mu \mathrm{l}$ buffer $\mathrm{F}$ containing $10 \mu \mathrm{M} \mathrm{SrtB}_{\Delta \mathrm{N} 26}$ and $20 \mu \mathrm{M}$ fluorogenic peptide in clear-bottomed, black polystyrene 384-well plates (Nunc). Plates were incubated for 48 hours at $37^{\circ} \mathrm{C}$, during which fluorescence (excitation $=340 \mathrm{~nm}$, emission $=490 \mathrm{~nm}$ ) was measured using a SpectraMax M3 plate reader (Molecular Devices). Five mM 2(trimethylamonium)ethylmethanethiosulfonate (MTSET, Affymetrix) was added to the reaction as indicated. Each experiment was performed in triplicate with a minimum of three biological replicates, and the results are presented as the means and the standard error of the data obtained. The two-tailed Student's T-test was used to analyze the data. MALDI analysis of FRET reaction samples was performed by the Protein and Nucleic Acid Chemistry Facility (University of Cambridge) to determine exact cleavage site within each peptide.

\section{Kinetic measurements}

Kinetic data for $\mathrm{SrtB}_{\Delta \mathrm{N} 26}$ were obtained by incubating varying concentrations of peptide $(8,10,20,40,80,160$, 200 and $240 \mu \mathrm{M})$ with $10 \mu \mathrm{M} \mathrm{SrtB}_{\Delta \mathrm{N} 26}$. All reactions were performed as described above, with fluorescence monitored every ten minutes over a 13 hour period. To correlate fluorescence signal, expressed as arbitrary relative fluorescence units (RFU), with the concentration of product formed, standard curves of the fluorophore Edans were collected. The linear segment of the fluorophore standard curve generated a conversion ratio of 703.9 RFU/ $\mu \mathrm{M}$ Edans. Initial velocities $(V)$ were determined from the progress curves and plotted against substrate concentration $[S]$. The data were fitted to a modified version of the Michaelis-Menten equation incorporating substrate inhibition using SciPy 0.11.0 in Python 2.7.3, where $V_{\max }$ is the maximal enzymatic velocity, $K_{m}$ is the Michaelis constant, and $K_{i}$ is the inhibitor dissociation constant for unproductive substrate 
binding. All data points were collected in triplicate, and the overall assay was run in duplicate.

\section{Identification of SrtB inhibitors}

The proprietary LeadBuilder virtual screening method (Domainex, Ltd) was used to interrogate a database (PROTOCATS) of 80,000 potential compounds which had been pre-selected as protease inhibitors. The virtual screening protocol used pharmacophoric and docking filters derived from analysis of the BaSrtB crystal structure (with which the C. difficile SrtB shows 70\% identity and 90\% similarity at the active site). Sixty-two compounds identified in this screen as potential SrtB inhibitors were obtained from Enamine, ChemBridge, and Key Organics, and solubilized in DMSO. Selected compounds and MTSET were incubated with $10 \mu \mathrm{M} \operatorname{SrtB}_{\Delta \mathrm{N} 26}$ at a range of concentrations in the FRET-based assay conditions described above, so that final DMSO concentrations were $\leq 3.75 \%$, a concentration shown to have no significant effect on control fluorescence (data not shown). IC50 values were determined by non-linear least squares fit to a four parameter sigmoidal function using SciPy 0.11.0 in Python 2.7.3.

\section{Additional files}

Additional file 1: Figure S1. RT-PCR analysis in C. difficile strain 630 of CD2718 and its predicted substrates. PCR reactions were performed with 630 cDNA that was prepared from cultures grown to early exponential (E), late exponential $(\mathrm{L})$ and stationary phase $(\mathrm{S}) \cdot \mathrm{M}=$ Hyperladder I (Bioline), $\mathrm{G}=630$ genomic DNA, $\mathrm{W}=\mathrm{dH}_{2} \mathrm{O}$. A "+ "indicates cDNA reaction with added reverse transcriptase, "-" indicates cDNA reaction without added reverse transcriptase (control for DNA depletion of RNA sample).

Additional file 2: Table S1. Primers used for RT-PCR analysis.

\begin{abstract}
Abbreviations
SrtA: Sortase A; SrtB: Sortase B; FRET: Fluorescence resonance energy transfer; MTSET: 2-(trimethylamonium)ethylmethanethiosulfonate; Dabcyl or $d$ : 4-([4-(dimethylamino)phenyl]azo)-benzoyl; Edans or e: 5-((2-Aminoethyl) amino)naphthalene-1-sulfonic acid; CDI: C. difficile infection; IPTG: Isopropyl $\beta-D-1$-thiogalactopyranoside; RFU: Relative fluorescence units.
\end{abstract}

\section{Competing interests}

The authors declare that they have no competing interests.

\section{Authors' contributions}

Laboratory work: EHD; experimental design: EHD, LFD, EV, SFC, MRM, EL, TRP, BWW; writing of manuscript: EHD, LFD, BWW. All authors read and approved the final manuscript.

\section{Acknowledgments}

We thank Jun Wheeler for MALDI mass spectrometry fingerprinting analysis of recombinant proteins; Mark Donahue for assistance with data analysis; Hayley Angove and Wendy Savory for assistance with development of the FRET-based assay and sortase protein expression, respectively. We thank Neil Fairweather, Johann Peltier, Helen A. Shaw and Madeleine Moule for critical reading of the manuscript.

\section{Funding}

This research was supported by funding from Wellcome Trust grant number 086418/Z/ and MRC grant number 49994717.

\section{Author details}

Pathogen Molecular Biology Department, London School of Hygiene and Tropical Medicine, Keppel Street, London WC1E 7HT, UK. Domainex Ltd, 162 Cambridge Science Park, Milton Road, Cambridge CB4 OGH, UK.

Received: 6 June 2014 Accepted: 12 August 2014

Published: 31 August 2014

\section{References}

1. Mazmanian SK, Ton-That H, Schneewind O: Sortase-catalysed anchoring of surface proteins to the cell wall of Staphylococcus aureus. Mol Microbiol 2001, 40(5):1049-1057.

2. Ton-That H, Faull KF, Schneewind O: Anchor structure of staphylococcal surface proteins. A branched peptide that links the carboxyl terminus of proteins to the cell wall. J Biol Chem 1997, 272(35):22285-22292.

3. Ton-That H, Mazmanian SK, Alksne L, Schneewind O: Anchoring of surface proteins to the cell wall of Staphylococcus aureus. Cysteine 184 and histidine 120 of sortase form a thiolate-imidazolium ion pair for catalysis. J Biol Chem 2002, 277(9):7447-7452.

4. Ton-That H, Mazmanian SK, Faull KF, Schneewind O: Anchoring of surface proteins to the cell wall of Staphylococcus aureus. Sortase catalyzed in vitro transpeptidation reaction using LPXTG peptide and $\mathrm{NH}(2)-\mathrm{Gly}(3)$ substrates. J Biol Chem 2000, 275(13):9876-9881.

5. Perry AM, Ton-That H, Mazmanian SK, Schneewind O: Anchoring of surface proteins to the cell wall of Staphylococcus aureus. III. Lipid II is an in vivo peptidoglycan substrate for sortase-catalyzed surface protein anchoring. J Biol Chem 2002, 277(18):16241-16248.

6. Ruzin A, Severin A, Ritacco F, Tabei K, Singh G, Bradford PA, Siegel MM, Projan SJ, Shlaes DM: Further evidence that a cell wall precursor $[C(55)$ MurNAc-(peptide)-GIcNAc] serves as an acceptor in a sorting reaction. J Bacteriol 2002, 184(8):2141-2147.

7. Spirig T, Weiner EM, Clubb RT: Sortase enzymes in Gram-positive bacteria. Mol Microbiol 2011, 82:1044-1059.

8. Mazmanian SK, Liu G, Jensen ER, Lenoy E, Schneewind O: Staphylococcus aureus sortase mutants defective in the display of surface proteins and in the pathogenesis of animal infections. Proc Natl Acad Sci U S A 2000, 97(10):5510-5515.

9. Mazmanian SK, Liu G, Ton-That H, Schneewind O: Staphylococcus aureus sortase, an enzyme that anchors surface proteins to the cell wall. Science 1999, 285(5428):760-763.

10. Kharat AS, Tomasz A: Inactivation of the srtA gene affects localization of surface proteins and decreases adhesion of Streptococcus pneumoniae to human pharyngeal cells in vitro. Infect Immun 2003, 71(5):2758-2765.

11. Pallen MJ, Lam AC, Antonio M, Dunbar K: An embarrassment of sortases a richness of substrates? Trends Microbiol 2001, 9(3):97-102.

12. Barnett TC, Scott JR: Differential recognition of surface proteins in Streptococcus pyogenes by two sortase gene homologs. J Bacteriol 2002, 184(8):2181-2191.

13. Bierne $H$, Mazmanian SK, Trost M, Pucciarelli MG, Liu G, Dehoux P, Jansch L, Garcia-del Portillo F, Schneewind O, Cossart P: Inactivation of the srtA gene in Listeria monocytogenes inhibits anchoring of surface proteins and affects virulence. Mol Microbiol 2002, 43(4):869-881.

14. Garandeau C, Reglier-Poupet H, Dubail I, Beretti JL, Berche P, Charbit A: The sortase SrtA of Listeria monocytogenes is involved in processing of internalin and in virulence. Infect Immun 2002, 70(3):1382-1390.

15. Gaspar AH, Marraffini LA, Glass EM, Debord KL, Ton-That H, Schneewind O: Bacillus anthracis sortase A (SrtA) anchors LPXTG motif-containing surface proteins to the cell wall envelope. J Bacterio/ 2005, 187(13):4646-4655.

16. Swaminathan A, Mandlik A, Swierczynski A, Gaspar A, Das A, Ton-That H: Housekeeping sortase facilitates the cell wall anchoring of pilus polymers in Corynebacterium diphtheriae. Mol Microbiol 2007, 66(4):961-974.

17. Mazmanian SK, Ton-That H, Su K, Schneewind O: An iron-regulated sortase anchors a class of surface protein during Staphylococcus aureus pathogenesis. Proc Natl Acad Sci U S A 2002, 99(4):2293-2298.

18. Maresso AW, Chapa TJ, Schneewind O: Surface protein IsdC and Sortase B are required for heme-iron scavenging of Bacillus anthracis. J Bacteriol 2006, 188(23):8145-8152.

19. Rupnik M, Wilcox MH, Gerding DN: Clostridium difficile infection: new developments in epidemiology and pathogenesis. Nat Rev Microbio/ 2009, 7(7):526-536. 
20. He M, Sebaihia M, Lawley TD, Stabler RA, Dawson LF, Martin MJ, Holt KE, Seth-Smith HM, Quail MA, Rance R, Brooks K, Churcher C, Harris D, Bentley SD, Burrows C, Clark L, Corton C, Murray V, Rose G, Thurston S, van Tonder A, Walker D, Wren BW, Dougan G, Parkhill J: Evolutionary dynamics of Clostridium difficile over short and long time scales. Proc Natl Acad Sci U S A 2010, 107(16):7527-7532.

21. Dingle KE, Griffiths D, Didelot $X$, Evans J, Vaughan A, Kachrimanidou M, Stoesser N, Jolley KA, Golubchik T, Harding RM, Peto TE, Fawley, Walker AS, Wilcox M, Crook DW: Clinical Clostridium difficile: clonality and pathogenicity locus diversity. PLoS One 2011, 6(5):e19993.

22. Stabler RA, Dawson LF, Valiente E, Cairns MD, Martin MJ, Donahue EH, Riley TV, Songer JG, Kuijper EJ, Dingle KE, Wren BW: Macro and micro diversity of Clostridium difficile isolates from diverse sources and geographical locations. PLoS One 2012, 7(3):e31559.

23. Cleary RK: Clostridium difficile-associated diarrhea and colitis - Clinical manifestations, diagnosis and treatment. Dis Colon Rectum 1998, 41(11):1435-1449.

24. Sebaihia M, Wren BW, Mullany P, Fairweather NF, Minton N, Stabler R, Thomson NR, Roberts AP, Cerdeno-Tarraga AM, Wang H, Holden MT, Wright A, Churcher C, Quail MA, Baker S, Bason N, Brooks K, Chillingworth T, Cronin A, Davis P, Dowd L, Fraser A, Feltwell T, Hance Z, Holroyd S, Jagels K, Moule S, Mungall K, Price C, Rabbinowitsch E, et al: The multidrug-resistant human pathogen Clostridium difficile has a highly mobile, mosaic genome. Nat Genet 2006, 38(7):779-786.

25. Liew CK, Smith BT, Pilpa R, Suree N, llangovan U, Connolly KM, Jung $M E$, Clubb RT: Localization and mutagenesis of the sorting signal binding site on sortase A from Staphylococcus aureus. FEBS Lett 2004, 571(1-3):221-226

26. Marraffini LA, Ton-That H, Zong Y, Narayana SV, Schneewind O: Anchoring of surface proteins to the cell wall of Staphylococcus aureus. A conserved arginine residue is required for efficient catalysis of sortase A. J Biol Chem 2004, 279(36):37763-37770.

27. Kelley LA, Sternberg MJ: Protein structure prediction on the Web: a case study using the Phyre server. Nat Protoc 2009, 4(3):363-371.

28. Zhang R, Wu R, Joachimiak G, Mazmanian SK, Missiakas DM, Gornicki P, Schneewind O, Joachimiak A: Structures of sortase B from Staphylococcus aureus and Bacillus anthracis reveal catalytic amino acid triad in the active site. Structure 2004, 12(7):1147-1156.

29. Stabler RA, He M, Dawson L, Martin M, Valiente E, Corton C, Lawley TD, Sebaihia M, Quail MA, Rose G, Gerding DN, Gibert M, Popoff MR, Parkhill J, Dougan G, Wren BW: Comparative genome and phenotypic analysis of Clostridium difficile 027 strains provides insight into the evolution of a hypervirulent bacterium. Genome Biol 2009, 10(9):R102.

30. Tulli L, Marchi S, Petracca R, Shaw HA, Fairweather NF, Scarselli M, Soriani M, Leuzzi R: CbpA: a novel surface exposed adhesin of Clostridium difficile targeting human collagen. Cell Microbiol 2013, 15(10):1674-1687.

31. Comfort D, Clubb RT: A comparative genome analysis identifies distinct sorting pathways in gram-positive bacteria. Infect Immun 2004, 72(5):2710-2722.

32. Schneewind O, Mihaylova-Petkov D, Model P: Cell wall sorting signals in surface proteins of gram-positive bacteria. EMBO J 1993 12(12):4803-4811.

33. Janulczyk R, Rasmussen M: Improved pattern for genome-based screening identifies novel cell wall-attached proteins in gram-positive bacteria. Infect Immun 2001, 69(6):4019-4026.

34. Pritz S, Wolf $Y$, Kraetke O, Klose J, Bienert M, Beyermann M: Synthesis of biologically active peptide nucleic acid-peptide conjugates by sortasemediated ligation. J Org Chem 2007, 72(10):3909-3912.

35. Matayoshi ED, Wang GT, Krafft GA, Erickson J: Novel fluorogenic substrates for assaying retroviral proteases by resonance energy transfer. Science 1990, 247(4945):954-958.

36. Ton-That H, Liu G, Mazmanian SK, Faull KF, Schneewind O: Purification and characterization of sortase, the transpeptidase that cleaves surface proteins of Staphylococcus aureus at the LPXTG motif. Proc Natl Acad Sci U S A 1999, 96(22):12424-12429.

37. Ton-That H, Schneewind O: Anchor structure of staphylococcal surface proteins. IV. Inhibitors of the cell wall sorting reaction. J Biol Chem 1999, 274(34):24316-24320

38. Dhar G, Faull KF, Schneewind O: Anchor structure of cell wall surface proteins in Listeria monocytogenes. Biochemistry (MOsC) 2000, 39(13):3725-3733.
39. Marraffini LA, Schneewind O: Anchor structure of staphylococcal surface proteins. V. Anchor structure of the sortase B substrate IsdC. J Biol Chem 2005, 280(16):16263-16271.

40. Race PR, Bentley ML, Melvin JA, Crow A, Hughes RK, Smith WD, Sessions RB, Kehoe MA, McCafferty DG, Banfield MJ: Crystal structure of Streptococcus pyogenes sortase $A$ : implications for sortase mechanism. J Biol Chem 2009, 284(11):6924-6933.

41. McDevitt D, Francois P, Vaudaux P, Foster TJ: Molecular characterization of the clumping factor (fibrinogen receptor) of Staphylococcus aureus. Mol Microbiol 1994, 11(2):237-248.

42. Ni Eidhin D, Perkins S, Francois P, Vaudaux P, Hook M, Foster TJ: Clumping factor B (ClfB), a new surface-located fibrinogen-binding adhesin of Staphylococcus aureus. Mol Microbiol 1998, 30(2):245-257.

43. Patti JM, Jonsson H, Guss B, Switalski LM, Wiberg K, Lindberg M, Hook M: Molecular characterization and expression of a gene encoding a Staphylococcus aureus collagen adhesin. J Biol Chem 1992, 267(7):4766-4772.

44. Cheng AG, Kim HK, Burts ML, Krausz T, Schneewind O, Missiakas DM: Genetic requirements for Staphylococcus aureus abscess formation and persistence in host tissues. FASEB J 2009, 23(10):3393-3404.

45. Weiss WJ, Lenoy E, Murphy T, Tardio L, Burgio P, Projan SJ, Schneewind O, Alksne L: Effect of srtA and srtB gene expression on the virulence of Staphylococcus aureus in animal models of infection. $J$ Antimicrob Chemother 2004, 53(3):480-486.

46. Bolken TC, Franke CA, Jones KF, Zeller GO, Jones $\mathrm{CH}$, Dutton EK, Hruby DE: Inactivation of the srtA gene in Streptococcus gordonii inhibits cell wall anchoring of surface proteins and decreases in vitro and in vivo adhesion. Infect Immun 2001, 69(1):75-80.

47. Mandlik A, Swierczynski A, Das A, Ton-That H: Corynebacterium diphtheriae employs specific minor pilins to target human pharyngeal epithelial cells. Mol Microbiol 2007, 64(1):111-124.

48. Jonsson IM, Mazmanian SK, Schneewind O, Bremell T, Tarkowski A: The role of Staphylococcus aureus sortase A and sortase B in murine arthritis. Microbes Infect 2003, 5(9):775-780.

49. Kang HJ, Coulibaly F, Proft T, Baker EN: Crystal structure of Spy0129, a Streptococcus pyogenes class B sortase involved in pilus assembly. PLoS One 2011, 6(1):e15969.

50. Chang C, Mandlik A, Das A, Ton-That H: Cell surface display of minor pilin adhesins in the form of a simple heterodimeric assembly in Corynebacterium diphtheriae. Mol Microbiol 2011, 79(5):1236-1247.

51. Frankel BA, Kruger RG, Robinson DE, Kelleher NL, McCafferty DG: Staphylococcus aureus sortase transpeptidase SrtA: insight into the kinetic mechanism and evidence for a reverse protonation catalytic mechanism. Biochemistry (Mosc) 2005, 44(33):11188-11200.

52. Dziarski R: Peptidoglycan recognition proteins (PGRPs). Mol Immunol 2004 40(12):877-886.

53. Schleifer KH, Kandler O: Peptidoglycan types of bacterial cell walls and their taxonomic implications. Bacteriol Rev 1972, 36(4):407-477.

54. Necchi F, Nardi-Dei V, Biagini M, Assfalg M, Nuccitelli A, Cozzi R, Norais N, Telford JL, Rinaudo CD, Grandi G, Maione D: Sortase A substrate specificity in GBS pilus 2a cell wall anchoring. PLoS One 2011, 6(10):e25300.

55. Weiner EM, Robson S, Marohn M, Clubb RT: The Sortase A enzyme that attaches proteins to the cell wall of Bacillus anthracis contains an unusual active site architecture. J Biol Chem 2010, 285(30):23433-23443.

56. Peltier J, Courtin P, El Meouche I, Lemee L, Chapot-Chartier MP, Pons JL: Clostridium difficile has an original peptidoglycan structure with a high level of $\mathrm{N}$-acetylglucosamine deacetylation and mainly 3-3 cross-links. J Biol Chem 2011, 286(33):29053-29062.

57. Oh KB, Oh MN, Kim JG, Shin DS, Shin J: Inhibition of sortase-mediated Staphylococcus aureus adhesion to fibronectin via fibronectin-binding protein by sortase inhibitors. Appl Environ Microbiol 2006, 70(1):102-106.

58. Maresso AW, Wu R, Kern JW, Zhang R, Janik D, Missiakas DM, Duban ME, Joachimiak A, Schneewind O: Activation of inhibitors by sortase triggers irreversible modification of the active site. J Biol Chem 2007, 282(32):23129-23139.

59. Oh K-B, Nam K-W, Ahn H, Shin J, Kim S, Mar W: Therapeutic effect of (Z)-3-(2,5-dimethoxyphenyl)-2-(4-methoxyphenyl) acrylonitrile (DMMA) against Staphylococcus aureus infection in a murine model. Biochem Biophys Res Commun 2010, 396(2):440-444.

60. Robichon C, Luo J, Causey TB, Benner JS, Samuelson JC: Engineering Escherichia coli BL21(DE3) derivative strains to minimize E. coli protein 
contamination after purification by immobilized metal affinity chromatography. Appl Environ Microbiol 2011, 77(13):4634-4646.

61. Monot M, Boursaux-Eude C, Thibonnier M, Vallenet D, Moszer I, Medigue C, Martin-Verstraete I, Dupuy B: Reannotation of the genome sequence of Clostridium difficile strain 630. J Med Microbiol 2011, 60(Pt 8):1193-1199.

62. Petersen TN, Brunak S, von Heijne G, Nielsen H: SignalP 4.0: discriminating signal peptides from transmembrane regions. Nat Methods 2011, 8(10):785-786.

63. Moller S, Croning MD, Apweiler R: Evaluation of methods for the prediction of membrane spanning regions. Bioinformatics 2001, 17(7):646-653.

doi:10.1186/s12866-014-0219-

Cite this article as: Donahue et al: Clostridium difficile has a single sortase, SrtB, that can be inhibited by small-molecule inhibitors. BMC Microbiology 2014 14:219.

\section{Submit your next manuscript to BioMed Central and take full advantage of:}

- Convenient online submission

- Thorough peer review

- No space constraints or color figure charges

- Immediate publication on acceptance

- Inclusion in PubMed, CAS, Scopus and Google Scholar

- Research which is freely available for redistribution 